\title{
Characteristics of the Biodiesel Palm Oil Methyl Ester Pool Fire
}

\author{
Mohd Rosdzimin Abdul Rahman ${ }^{1, a}$, Raj Mohan ${ }^{2}$, Kin Yuen Leong ${ }^{1}$ and Siti Noor Aliah Baharom ${ }^{2}$ \\ ${ }^{1}$ Dept. of Mechanical, Faculty of Engineering, Universiti Pertahanan Nasional Malaysia, Kem Sg. Besi, 57000, Kuala Lumpur, Malaysia \\ ${ }^{2}$ Malaysia Agricultural Research and Development Institute, Serdang, Selangor, Malaysia
}

\begin{abstract}
The characteristics of biodiesel pool fires with palm oil methyl ester concentrations of $7 \%$ by volume in various pan diameter sizes $(0.05 \mathrm{~m}, 0.10 \mathrm{~m}$ and $0.15 \mathrm{~m})$ were studied. Initially, biodiesel was heated on a hot plate to increase the temperature close to the flash point temperature. Later fuel was ignited and stable pool fire formed. Flame temperature along the centerline pool fire from flame base to flame tip were measured. Flame temperature shows that the temperature at flame base is higher than that the flames tip. This is due to the complete burning occurs near flame base and at flame tip incomplete burning exists. Incomplete burning produces yellow flame appearance. Moreover, the mass burn rate varies linearly with pan size. Small diameter pan produces low mass burn rate compared to the large diameter pan. Low and high mass burn rate contributes to the flame height. Flame with higher mass burn rate is longer than that the low mass burn rate. Thus, the characteristic of the biodiesel palm oil methyl ester is successfully studied in the present study.
\end{abstract}

\section{Introduction}

Alternative fuels are developed to replace petroleum-based fuels due to the gas exhaust emission issues and to promote energy security. Biodiesel is one category of the alternative fuels that is environmental friendly. It is used widely in Malaysia since 2010. Started with $\mathrm{B} 5$ and the recent $\mathrm{B} 7$ is in the market since November 2014. Biodiesel in Malaysia is made from palm oil methyl ester. Methyl ester is derived from vegetable oil (biodiesel). Conversion of crude palm oil to palm oil methyl ester (POME) was successfully done by The Palm Oil Research Institute of Malaysia (PORIM) through trans-esterification. Studies on the engine performance using POME were done. Moreover, due to low sulphur content $(1.112 \mathrm{wt} \%)$ of the POME, clean emission was produced. Performance studies on the engine using biodiesel and POME were reported by various researchers [1-5]. However, the fire safety precautions also must be taken into consideration to ensure safe storage and fueling. Studies on the fire characteristic of other biodiesel [6-8] have been carried out. However, there is no scientific study on the POME fire behavior. Knowledge of the fire behaviors will lead to better safety and fire's control when it happens as the use of biodiesel becomes widespread and increase the possibility of fire occurrence.

Pool fire is used to imitate the fire scenario including fires ranging in size from a $0.005 \mathrm{~m}$ to fire diameter as large as $10^{5}$ [9]. Lots of studies on the pool fire using different types of fuel have been done. The important parameters in analyzing pool fire are flame characteristic and shape, pulsation frequency, flame

\footnotetext{
a Corresponding author: rosdzimin $@$ gmail.com
}

height, detailed structure of the flame, enthalpy balance in the flame, enthalpy balance at the fuel surface, mass vaporization rate and radiative emission [9]. These parameters are required in modeling and combating fires.

Biodiesel fire research received less attention in fire research community. Only Refs. [6-8] conducting biodiesel pool fire research recently. In 2011, Ref. [6] studied on the biodiesel pool fires of canola, soy and blends with petroleum diesel. Ref. [6] observed that the fuel regression rate of the surface in all pans size was comparable. It is also revealed that burning rate of the fuel mass as well as the surface regression rate varied non-monotonically with the concentration of biodiesel in the blend. Later, Ref. [7] blended canola methyl ester, soy methyl ester with Jet A fuel. They found that the fuel mass burning rate in the small pan was less than that of larger pan for all type of flames. Moreover, the fuel surface regression rate was reduced when the biodiesel concentration in the blends was greater than $75 \%$ in volume. Since there is no study on the POME fire behavior, which is important for safety, therefore, the objective of the study is to investigate the pool fires characteristics of palm oil methyl ester in various pan diameters.

\section{Experiment Set Up}

An experimental setup diagram is shown in Fig. 1.The fuel pan was placed on a top of hot plate in this experiment. Three cylindrical aluminum pans were used to fire the biodiesel; The pan's inner diameter were 0.05 $\mathrm{m}, 0.10 \mathrm{~m}$ and $0.15 \mathrm{~m}$ while its height is $0.1 \mathrm{~m}$. The pans 
were filled with the fuel at various volumes. A $0.5 \mathrm{~cm}$ gap was left between the biodiesel surface and the container lid. Gap between the lid and biodiesel surface serves two purposes. There are: to allow volumetric expansion of biodiesel upon heating and also to prevent spilling. Six K-type thermocouples were spaced at $0.02 \mathrm{~m}$ vertically started at $0.01 \mathrm{~m}$ above the container lid. Flames temperatures were recorded by the thermocouples as shown in Fig. 1. Initially the hot plate was turned on and once the fuel reached flash point temperature, an igniter was used to ignite the biodiesel. The hot plate was turned off and the temperatures were recorded when the fire was sustained. When a fire was sustained, the hot plate was turned off and all the data were recorded. The flame height is measured by investigate the flame with scale on it side.

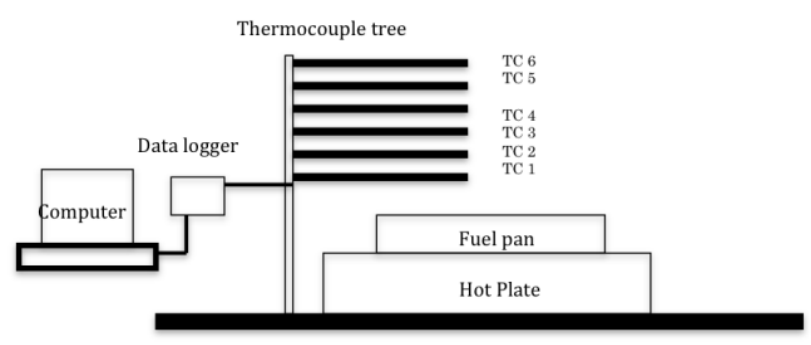

Figure 1. Schematic diagram of the experimental setup.

\section{Results and discussion}

Figure 2 shows photographs of the biodiesel flames at various pan's diameter. The flames were sensitive to the ambient wind condition and yellow color is attributed to the incomplete combustion. Moreover, $0.05 \mathrm{~m}$ pan produces laminar flame. On the other hand $0.1 \mathrm{~m}$ and $0.15 \mathrm{~m}$ produces flame in a transition regime. This result agreed with Ref. [9]. The flame height was $18 \mathrm{~cm}$ for the $0.05 \mathrm{~m}$ diameter pan (Fig. 3) and increase monotonically with increase in pan diameter. The increase of pan diameter increases flame height is due to increase in mass burn rate. Moreover, high fuel mass burn rate leads to higher heat release rate, thus increases flame height. It can be seen in Fig. 4, the fuel mass burn rate of $0.05 \mathrm{~m}$ diameter pan was significantly smaller than that of the $0.15 \mathrm{~m}$ diameter pan flames (Fig. 4). Higher mass burn rate for large diameter pan is because of more heat being transferred by conduction to the fuel. This can be explained by theory of heat transfer in pool fire.

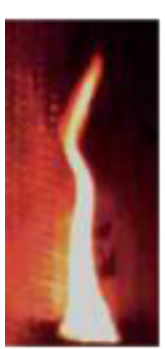

$5 \mathrm{~cm}$

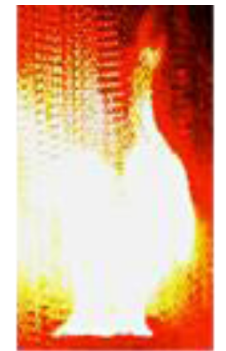

$10 \mathrm{~cm}$

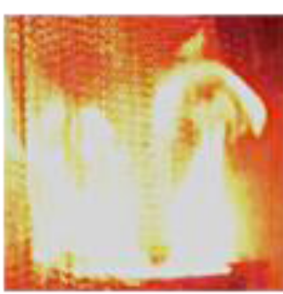

$15 \mathrm{~cm}$
Figure 2. Photograph of the biodiesel palm oil methyl ester pool fire at various pan diameters.

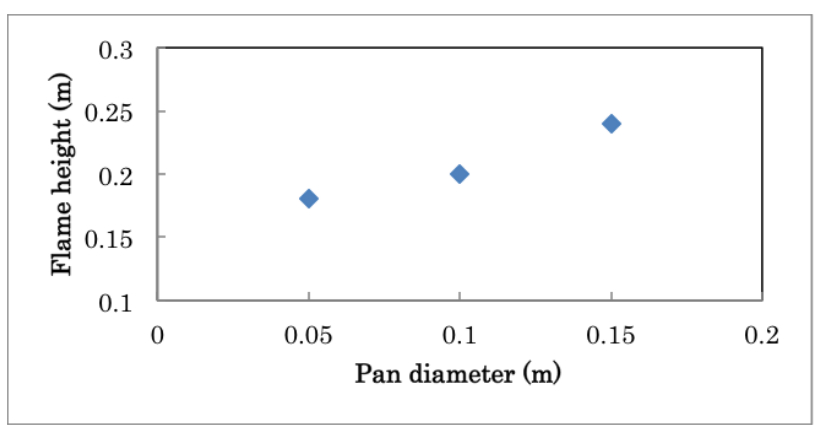

Figure 3. Flame height of the biodiesel palm oil methyl ester pool fire at various pan diameters.

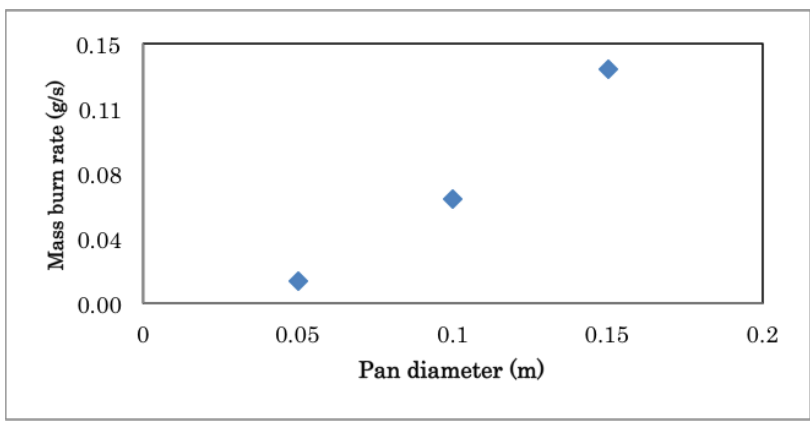

Figure 4. Mass burn rate of the biodiesel palm oil methyl ester pool fire at various pan diameters. 

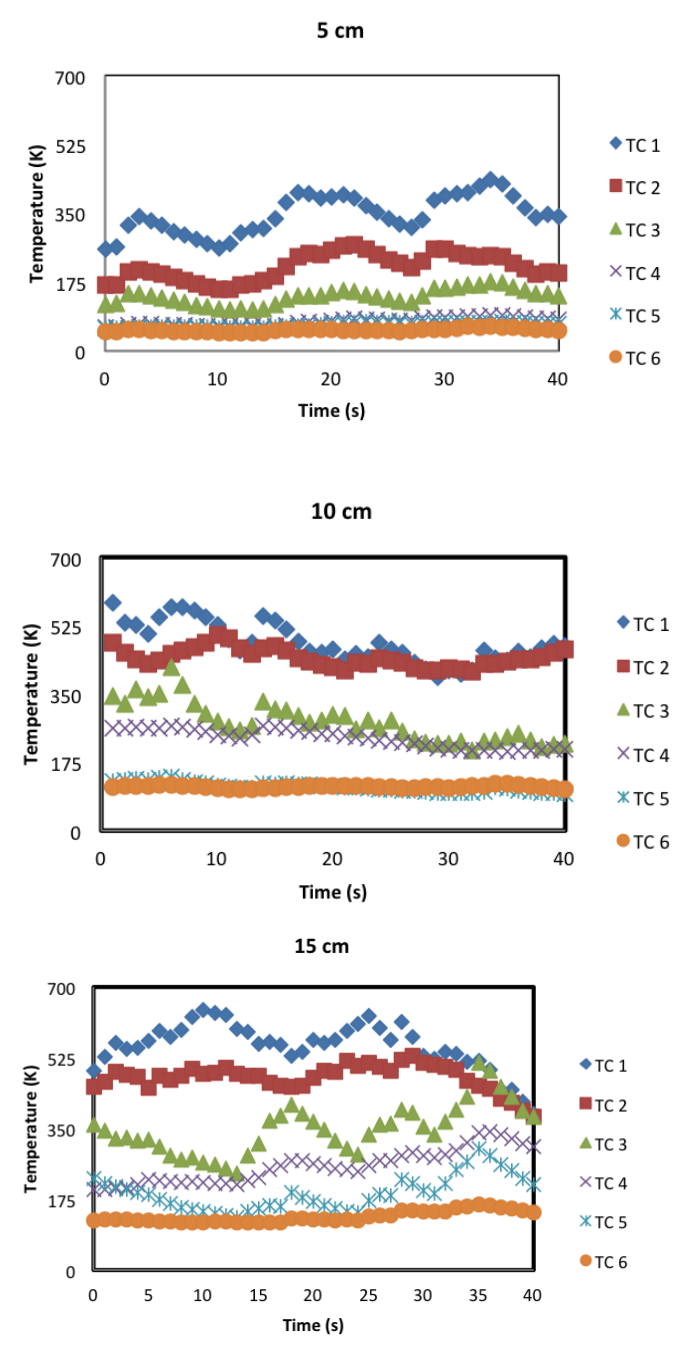

Figure 5. Flame temperature profile of the biodiesel palm oil methyl ester pool fire at various pan diameters.

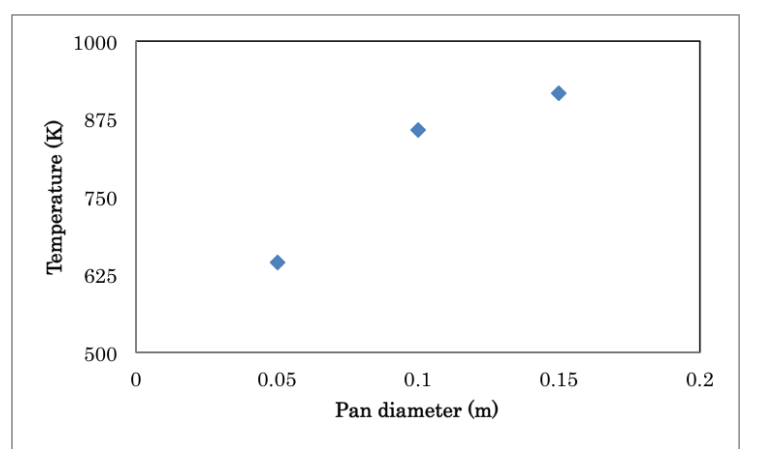

Figure 6. Highest temperature of the biodiesel palm oil methyl ester pool fire at various pan diameters.

\section{Conclusions}

The present study investigate combustion characteristics of pool fires biodiesel palm oil methyl ester fuel in various pan diameters. The flame appearance, fuel mass burn rate, temperature profile were measured. From this study, it can be concluded that: (a) More heat is being transferred by conduction in large pan resulted smaller mass burning rate from small container flames compared to that of large container flame.

(b) Smaller pan produced shorter flame due to the lower rate of heat release

(d) Similar temperature profiles were observed for all type of flames. The maximum temperature was recorded at the flame base attributed to complete combustion.

\section{Acknowledgements}

The authors would like to be obliged to Universiti Pertahanan Nasional Malaysia for providing laboratory facilities and financial assistance under project no. UPNM/2014/GPJP/TK/6.

\section{References}

1. A. Murugesan, C. Umarani, R. Subramanian and N. Nedunchezhian , Renewable and Sustainable Energy Reviews, 13, 653-662 (2009)

2. E Sadeghinezhad, S. N. Kazia, A. Badarudin, C. S. Oon N.M. Zubir and Mohamad Mehrali, Renewable and Sustainable Energy Reviews, 28, 410-42 (2013)

3. Mofijur M, Masjuki HH, Kalam MA, Atabani AE, Fattah IMR, Mobarak HM., Industrial Crops and Products, 53, 78-84 (2014)

4. A. Sanjid, H.H. Masjuki, M.A. Kalam, S.M.A. Rahman, M.J. Abedin, S.M. Palash, Journal of Cleaner Production, 65, 295- 303 (2014)

5. Ahman, S. M. A., Masjuki, H. H., Kalam, M. A., Abedin, M. J., Sanjid, A., \& Rahman, M. M.. Renewable Energy, 68, 644-650 (2014)

6. Tran V., Morton C., Parthasarathy R. N. and Gollahalli S. R., 9th Annual International Energy Conversion Engineering Conference USA, (AIAA 2011-6013)

7. Tran V., Morton C., Parthasarathy R. N. and Gollahalli S. R., 10th Annual International Energy Conversion Engineering Conference USA, (AIAA 2012-3722)

8. Tran V., Morton C., Parthasarathy R. N. and Gollahalli S. R., International Journal of Green Energy, 11, 595-610 (2014)

9. Hamins A., Kashiwagi T., and Buch R., Fire Resistance of Industrial Fluids, ASTM STP 1284, American Society for Testing and Materials, 1995. 